\title{
EDUCAÇÃO E DEMOCRACIA: FORMAÇÃO POLÍTICA PARA A CONVIVÊNCIA EM UMA SOCIEDADE PLURAL
}

\section{EDUCATION AND DEMOCRACY: POLITICAL FORMATION FOR A LIVING IN A PLURAL SOCIETY}

\author{
Telmo Marcon* \\ Universidade de Passo Fundo, Professor e pesquisador do Programa de Pós- \\ Graduação em Educação
}

Resumo: Com o presente artigo, objetivou-se refletir sobre os desafios de uma educação para a democracia no contexto das sociedades complexas, nas quais a diversidade e a pluralidade se evidenciam com muita intensidade. Buscando alcançar conta esse objetivo, no artigo, contextualizam-se algumas críticas à democracia, analisam-se alguns pressupostos de uma educação para a democracia e se conclui apontando alguns desafios postos às instituições sociais, particularmente à escola, no sentido de cumprir sua função de formadora intelectual e política dos cidadãos. Defende-se, aqui, a tese de que a democracia, concebida como organização política e como modo de vida, constitui-se em uma perspectiva fecunda para o enfrentamento e a superação de conflitos e para uma convivência social fundamentada no diálogo.

Palavras-chave: Educação. Política educacional. Democracia. Gestão democrática.

\begin{abstract}
With this study, we aimed to reflect about the challenges of an education for democracy in the context of complex societies, in which diversity and plurality are evidenced with more intensity. Seeking to achieve this goal, in this study, some criticisms to democracy are contextualized, some assumptions of an education to democracy are analyzed and the study is concluded pointing to some challenges placed to the social institutions, particularly to the school, in order to fulfill its function of intellectual and
\end{abstract}

\footnotetext{
* Pós-doutor em Educação intercultural pela Universidade Federal de Santa Catarina; Doutor em História Social pela Pontifícia Universidade Católica de São Paulo.
} 
political forming of citizens. The thesis here defended is that democracy, conceived as a political organization and a way of life, constitutes a fecund perspective for facing and overcoming conflicts and for a social coexistence founded in the dialogue.

Keywords: Education. Educational policy. Democracy. Democratic administration.

\section{INTRODUÇÃO}

Para introduzir a discussão, é importante destacar que o tema proposto abre inúmeras possibilidades que demandariam muitos esforços. Nos limites do presente artigo, pretendeu-se problematizar a questão da formação política para a convivência democrática em uma sociedade plural, em outras palavras, a educação para a democracia. A democracia concebida tanto como forma de governo quanto como modos de vida vem sendo, nos últimos anos, objeto de contestação, mas também de afirmação enquanto possibilidade de participação e de convivência em sociedades plurais. $\mathrm{O}$ conceito de democracia, assim como tantos outros, entre os quais, os de cidadania, tem sido usado de múltiplas formas e com distintos significados e interesses. No âmbito das políticas sociais, mais especificamente as educacionais, o conceito de democracia vem ganhando centralidade, mesmo em instituições multilaterais como o Banco Mundial. Em vista dos usos indiscriminados e para tantos fins é que o conceito de democracia corre risco de perder seu conteúdo histórico e revolucionário. O problema não é a centralidade que o conceito vem ganhando, mas os seus usos. Ocorrem apropriações desse conceito sem as devidas reflexões críticas. Ele tem sido muito utilizado como mediação para estudos de caso em escolas e outras instituições, apontando avanços ou, ao contrário, limitações. Atualmente, é difícil a elaboração de um Projeto Político-Pedagógico sem que o conceito de democracia ou de gestão democrática esteja posto. Parece ser uma necessidade que isso apareça e se constitua em uma forma de administrar a educação. Quais as implicações de uma gestão democrática para os sujeitos diretamente envolvidos nos processos pedagógicos e para os que não atuam diretamente? Que exigências são imprescindíveis para que uma gestão se torne efetivamente democrática? Quais as concepções de democracia vulgarmente utilizadas? Pode-se falar em democracia no singular?

Independente das contestações e dos usos que são feitos, a democracia, como reconhecem Santos e Avritzer (2009, p. 39), “[...] assumiu um lugar central no campo político durante o século XX. Se continuará a ocupar esse lugar no século em que agora entramos, é uma questão em aberto." Não há dúvidas de que essa ideia continua sendo vital no século XXI. Não faltam exemplos que evidenciam a inca- 
pacidade de instituições, grupos, classes sociais e governantes em trabalhar com a diversidade e a oposição política. Mesmo tendo essa centralidade, a democracia tanto em sua fundamentação teórica (normativa) quanto em experiências históricas concretas (realismo) vem sendo alvo de muitas críticas e questionamentos em relação ao seu alcance e potencialidade, especialmente em contextos de sociedades complexas, plurais socioculturalmente e profundamente desiguais socioeconomicamente. Algumas dessas críticas não são novas e já foram elaboradas, de alguma forma, por Platão (2000) e Aristóteles (1997).

Colocar em pauta a relação entre educação e democracia suscita um conjunto de questionamentos: de que forma avançar para além da democracia formal? Que concepções de democracia podem contribuir efetivamente para enfrentar os grandes desafios postos pelas sociedades complexas e plurais? É possível equalizar democracia e o capitalismo? Como pensar a questão da democracia representativa em um contexto de classes sociais e de profundas desigualdades socioeconômicas? Quais as potencialidades da democracia participativa para superar os limites do formalismo democrático? Quais as possibilidades de uma democracia de alta intensidade em contraposição à democracia de baixa intensidade, conforme proposição de Santos e Avritzer (2009, p. 39-82)? Quais as implicações decorrentes de uma compreensão de democracia concebida como "[...] forma de vida associada, de experiência conjunta e mutuamente comunicada" e não apenas como uma forma de governo, conforme aponta Dewey (1979, p. 93)? Como a democracia, enquanto forma de organizar a vida pública, pode abranger a diversidade e a pluralidade? Em que medida a gestão democrática do poder possibilita a superação de interesses individuais, privatistas e corporativos?

Esses questionamentos justificam o esforço que muitos pesquisadores vêm fazendo no sentido de pensar a democracia como forma de governo e também como modo de vida. No caso brasileiro, essa discussão ganha relevância por várias razões, entre as quais, destacam-se três:

a) a nossa incipiente experiência política democrática que, pela primeira vez no Brasil, aproxima-se de quatro décadas, visto que a história tem sido, desse ponto de vista, profundamente autoritária e ditatorial;

b) a emergência de camuflados e falsos discursos que associam democracia com governo fraco, anarquia e corrupção e, por isso, querem fazer crer que formas autoritárias de exercício do poder permitem superar os problemas socioeconômicos e políticos; 
c) as dificuldades das classes dominantes (conservadoras), com expressivo apoio de setores midiáticos, em conviver com a diversidade e a pluralidade.

Em momentos de conflitos e de tensões, esses setores clamam por intervenções autoritárias. Existem muitas outras razões, mas essas três justificam a reflexão sobre os desafios de educar para a democracia.

\section{CRÍTICAS À DEMOCRACIA}

Cunningham (2009) elenca um conjunto de críticas feitas à democracia e destaca sete delas, formuladas desde os filósofos gregos passando pela Idade Moderna até a atualidade. Considerando a importância e a atualidade dessas críticas, elas serão retomadas a partir das reflexões que Cunningham faz na obra: Teorias da democracia: uma introdução crítica.

A primeira crítica diz que a democracia é a tirania da maioria. Essa crítica não é recente na história e se fundamenta na ideia de que, na democracia, a maioria vence e o poder é delegado aos representantes dessa maioria. A tirania da maioria decorre da imposição dessa maioria sobre a minoria (CUNNINGHAM, 2009, p. 25). Essa parece ser uma das preocupações de Tocqueville quando analisa o tema: Do uso que fazem os americanos da associação na vida civil. Ao iniciar esse capítulo, diz que não pretende “[...] falar daquelas associações políticas com auxílio das quais os homens procuram defender-se contra a ação despótica de uma maioria ou como as usurpações do poder real [...]" (TOCQUEVILLE, 1977, p. 131). Para o autor, à medida que o cidadão se torna "[...] individualmente mais fraco" e for incapaz de preservar individualmente sua liberdade e não aprender a arte de unir-se a seus semelhantes para defendê-la, “[...] a tirania cresceria necessariamente com a igualdade.” (TOCQUEVILLE, 1977, p. 131).

Uma segunda crítica à democracia trata da massificação da cultura e da moral. Qual é o problema de fundo? Nessa crítica, há uma compreensão de que o poder da maioria tende a incluir, obrigatoriamente, setores populares com baixo nível cultural e moral. Subjacente a essa crítica, há uma compreensão de que os valores da nobreza ou da aristocracia são referência. Nesse caso, diz Cunningham (2009, p. 27-28), o limite da democracia deve-se ao fato de que os padrões culturais da maioria dominam e "de que esses padrões serão culturalmente depreciados", ou seja, o povo teria "gostos culturais simples e básicos". Ao focar o princípio da igualdade, pessoas refinadas seriam ignoradas ou, pelo menos, colocadas no mesmo nível das demais. 
Parte das críticas formuladas por Platão (2000) e, em certo sentido, também por Aristóteles (1997) à democracia tem esse problema como pressuposto. O problema para Platão (2000, p. 331, tradução nossa) é que a democracia é um “[...] regime agradável, sem chefe, porém, artificioso, que distribui a igualdade tanto aos iguais quanto aos que não o são." Como observa Francisco Márquez Cabrera, na introdução que faz da obra La República, existem elementos do contexto histórico que justificam a preferência de Platão pela aristocracia. Segundo Cabrera, Platão “[...] tem sua própria imagem formada da democracia de sua cidade que reflete nesta obra como um demo menor de idade e insensata e a alguns demagogos que se arrastam a seus caprichos abusando de sua incapacidade e falta de sentido." (PLATÃO, 2000, p. 12, tradução nossa). Aristóteles (1997, p. 205) também trabalha com uma distinção fundamental entre aristocratas e povo: "Enquanto a oligarquia se caracteriza pela nobreza, riqueza e educação, as qualificações populares são o contrário destas, ou seja, origem humilde, pobreza e atividades vulgares." Macpherson (1978, p. 16-17) sintetiza essa problemática dizendo:

Não é novidade absolutamente alguma observar que no principal do pensamento político tradicional do Ocidente, de Platão a Aristóteles até os séculos XVIII e XIX, a democracia, caso se pense nela alguma vez, era definida como norma para os pobres, ignorantes e incompetentes, à custa das classes possidentes instruídas e ociosas. A democracia, no modo de ver das camadas mais elevadas das sociedades divididas em classes, significava governo de classe, governo pela classe errada.

A terceira crítica incide sobre a ineficácia do governo democrático. Ela parte da ideia de que, mesmo sendo elaborados objetivos comuns, "[...] a democracia impediu a habilidade dos governos de executá-los, por encorajar pessoas a pedir demais do Estado, dessa forma sobrecarregando-o economicamente." (CUNNINGHAM, 2009 , p. 28). Segundo o autor, em 1975, uma comissão conhecida como Trilateral apresentou um relatório conhecido como a crise da democracia, no qual destacou as "disfunções" decorrentes da própria democracia e das disputas de interesses. Isso seria em razão do igualitarismo democrático "[...] que retirou a legitimidade da autoridade, de forma mais importante, em instituições como a família, a igreja, a escola e o exército." (CUNNINGHAM, 2009, p. 27). Consequentemente, houve fortalecimento dos espaços comunitários em detrimento de autoridade geral.

A quarta crítica à democracia trata da dificuldade de solucionar conflitos sociais profundos. Essa crítica parte do princípio de que uma democracia pode funcionar bem em sociedades sem profundas divergências e graves conflitos socioeconômicos, ou seja, ela funciona bem quando a população for relativamente homogênea. 
Assim, diz Cunningham (2009, p. 28), “[...] quando divisões profundas e persistentes existem em uma sociedade, a democracia exacerba a discórdia, assim como partidos conflitantes buscam colocar o governo a serviço de seus fins particulares ou, falhando isso, transformam os fóruns governamentais em campos de batalha." A discussão feita por Macpherson (1978, p. 9-28) sobre a democracia até o século XIX identifica duas grandes tendências: uma sociedade sem classe e uma de classe única. "Espero que esse breve exame dos modelos de democracia de antes do século XIX seja suficiente para amparar minha generalização de que todos eles se ajustavam a uma sociedade sem classes ou a uma sociedade de classe única.” (MACPHERSON, 1978, p. 26).

Uma quinta crítica é definida por Cunningham (2009, p. 31) como demagogia e o espaço vazio da democracia. O ponto de partida dessa crítica fundamenta-se no oportunismo de demagogos em manipularem a opinião pública. Essa fragilidade pode desembocar em uma demagogia do tipo populista, como também em forma de governos autoritários, mascarados de democracia. "Demagogos são especialistas ao tomar vantagem cínica desses aspectos da democracia, e os populistas autoritários usam-nos para justificar o governo autoritário.” (CUNNINGHAM, 2009, p. 31). Platão (2000), Aristóteles (1997), Tocqueville (1977), entre outros despertaram atenção, por diferentes caminhos, dos riscos de demagogos utilizarem meios para manipular os interesses legítimos de coletividades em favor de seus interesses próprios. Nessa direção, pode-se pensar no poder crescente de marqueteiros em processos eleitorais e na capacidade de produzirem personagens sem trajetórias políticas e sem compromissos com a própria democracia. Essa crítica tem um conjunto de elementos empíricos que permitem fundamentá-la. À medida que a participação de diferentes atores sociais for bloqueada ou instrumentalizada, crescem os riscos de esvaziamento da própria democracia, que entra em descrédito enquanto forma de enfrentar e resolver conflitos.

A sexta crítica incide sobre a forma mascarada com que governos opressores governam sob a aparência democrática. Essa crítica parte da constatação de que estruturas burocráticas e partidárias, assim como de processos eleitorais, comprometem efetivamente o "governo do povo". São interesses de classe (alta), de raça (dominante) e de gênero (masculino), que se sobrepõem aos objetivos republicanos. Mesmo com todos esses interesses (classes, raças e gênero) em disputa, a democracia formal mantém uma aparência de universalidade. Nesse caso, cabe perguntar: em uma democracia, quem realmente governa e quem não governa? As críticas formuladas por Santos e Avritzer (2009, p. 39-82) à democracia de baixa intensidade ajudam a compreender e fundamentar essa tese. Além de um esvaziamento político e participativo ocorre um uso indiscriminado do conceito de democracia. De que forma organismos 
multilaterais, como o Banco Mundial, atuam de forma democrática? Em seus documentos, esse conceito está presente, especialmente quando se trata da educação.

A sétima crítica é resumida por Cunningham (2009, p. 32) como democracia irracional. Essa crítica parte do pressuposto de que a democracia é irracional por ser um "[...] governo de massas ignorantes do povo, incapazes de conhecer seus interesses ou restringir seus impulsos emocionais, estando fora de controle." Essa posição cruza-se com elementos das críticas anteriores, tendo elementos de Platão e Aristóteles a partir de críticas que fizeram às experiências contemporâneas. Um dos argumentos de Aristóteles, por exemplo, é de que em uma democracia é fundamental a discussão pública, a qual, por sua vez, exige a participação dos cidadãos. O autor questiona: como os pobres podem abrir mão de seus afazeres e custear os deslocamentos para participar dos debates públicos?

\footnotetext{
O melhor povo é constituído de agricultores, porquanto é possível implantar a democracia onde o povo em sua maioria vive da agricultura e da pecuária; pelo fato de não terem posses, os agricultores estão sempre ocupados, e não podem por isto reunir-se frequentemente em assembleia, pois para satisfazerem às suas necessidades básicas eles consomem todo o tempo no trabalho [...] (ARISTÓTELES, 1997, p. 207).
}

Essas críticas ajudam a contextualizar o debate sobre democracia e evidenciar que ele não é pacífico. Muitas críticas são feitas tanto em relação aos pressupostos normativos quanto aos procedimentos práticos. São questões que precisam ser postas quando da realização de pesquisas, tanto as que tratam da democracia no sentido amplo quanto as que discutem experiências de gestão democrática da educação. É fundamental pensar em educação e democracia em relação a suas potencialidades e também a seus limites e desafios.

\section{EDUCAÇÃO E DEMOCRACIA EM SOCIEDADES PLURAIS}

Contextualizadas as principais críticas à democracia, é fundamental pensá-la do ponto de vista da educação no contexto das sociedades complexas. Para Santos e Avritzer (2009), o modelo de democracia que se tornou hegemônico primou por procedimentos formais, por conseguinte, não enfrentou de modo suficiente os desafios postos pelas sociedades complexas e plurais. Nesse sentido, a democracia é restritiva na medida em que limita a participação em processos eleitorais. Em contraposição a essa concepção, sem negá-la evidentemente, esses autores destacam a importância da participação, ou como denominam, democracia de alta intensidade. A crítica que formu- 
lam à concepção dominante de democracia se deve ao esvaziamento do seu potencial crítico e participativo. À proporção que se tornou meramente formal, perdeu sua força revolucionária, adequando-se às demandas da sociedade capitalista e assumindo funções profundamente conservadoras. Como já foi observado, organismos multilaterais, entre os quais, o Banco Mundial e o Fundo Monetário Internacional, contribuem para esse esvaziamento pelo fato de que também fazem uso desse conceito de modo acrítico.

A defesa de uma democracia de alta intensidade é justificada em razão da necessidade de os cidadãos participarem de todos os processos nos diferentes espaços institucionais, na discussão dos problemas e na tomada de decisões. Dada a pluralidade de experiências sociais, não existe um único modelo de democracia. Para atender à essa pluralidade, Santos e Avritzer (2009, p. 71) introduzem o conceito de demodiversidade, entendida como "[...] a coexistência pacífica ou conflituosa de diferentes modelos e práticas democráticas.” Em um contexto de crescente globalização econômica, é fundamental pensar em formas alternativas de participação e decisão que valorizem as escalas local, regional e nacional, mas, concomitantemente, projetem-se internacionalmente. Em outras palavras, é fundamental a identificação de experiências em construção que carregam potencialidades transformadoras, dando-lhes visibilidade. A democracia representativa continua sendo uma referência importante, mas é fundamental agregar-lhe outras formas de democracia participativa, condição efetiva para enfrentar e superar os interesses individuais e corporativos, bem como os conflitos sociais, peculiares ao contexto atual.

Nussbaum é uma pesquisadora que faz uma defesa vigorosa da democracia e do papel das instituições educativas, particularmente da Universidade e das ciências humanas para a sua efetivação. Diz isso em um contexto em que a democracia se revela frágil em relação ao poder econômico globalizado, mas também aos limites das instituições educativas em formar para a vida democrática. A respeito, diz:

Deveríamos redobrar a aposta naquilo que a educação contribui
para manter viva a democracia. Ainda que ao final descobrísse-
mos que não correm tantos perigos como eu creio, é evidente
que são vulneráveis e que se encontram sob uma enorme pres-
são na era da globalização econômica. (NUSSBAUM, 2010, p.
161 , tradução nossa).

Duas ideias podem ser destacadas desse fragmento: primeiro, que a democracia depende de processos educativos, ou seja, não há como pensar em sociedades democráticas sem uma educação que prepare democraticamente e, em segundo, que o poder do mercado resultante da globalização econômica tende a transformar a educação em mercadoria a serviço de interesses privados, ou seja, não democráticos. 
Suas reflexões desafiam a pensar no papel das disciplinas humanísticas no âmbito das universidades, condição para a cidadania e para a democracia. Nesse contexto, é fundamental pensar no papel das instituições educativas na formação de cidadãos críticos e capacitados para participarem, opinarem e contribuírem nas decisões.

Benevides é outra autora, brasileira, que traz contribuições importantes para pensar as relações entre educação e democracia. No entanto, ela vai além, ao vincular essa discussão com a relação à cidadania e aos direitos humanos. Ao tratar da educação para a democracia, destaca duas dimensões:

[...] a formação para os valores republicanos e democráticos e a formação para a tomada de decisões políticas em todos os níveis, pois numa sociedade verdadeiramente democrática ninguém nasce governante ou governado, mas pode vir a ser, alternativamente - e mais de uma vez no curso da vida - um ou outro. (BENEVIDES, 1996, p. 226).

Para que isso se efetive é fundamental, segundo Benevides (1996, p. 226227), superar três desafios: a formação intelectual e a informação (trata-se de conhecer para melhor escolher); a educação moral (vinculada a uma didática dos valores republicanos e democráticos que não se aprendem apenas intelectualmente, mas, sobretudo, pela consciência ética que envolve sentimentos e razão, coração e mente); e a educação do comportamento (aprendizado desde a escola primária de hábitos de tolerância, cooperação e subordinação dos interesses individuais ao interesse geral). A educação para a democracia, conclui Benevides (1996, p. 227), “[...] exige conhecimentos básicos da vida social e política e uma correspondente formação ética."

No Brasil, segundo Benevides (1996), é comum o uso de expressões como “educação do cidadão" e "educação para a cidadania". No entanto, são expressões usadas muito mais como retórica do que práticas democráticas efetivas. O problema é que não existe, ainda, “[...] a educação para a democracia, entendida, a partir da óbvia universalização do acesso de todos à escola, tanto para a formação de governados quanto de governantes.” (BENEVIDES, 1996, p. 224). Essa autora destaca cinco pontos que considera importantes em um programa de investigação sobre a democracia:

a) em que consiste a educação para a democracia e do que ela se diferencia;

b) a grande influência do pensamento clássico sobre a educação do cidadão;

c) as principais questões em torno dos valores republicanos e democráticos; 
d) onde deve ser desenvolvida a educação democrática;

e) os paradoxos da educação para a democracia (BENEVIDES, 1996, p. 225).

Para a autora, é fundamental a aproximação entre democracia e direitos humanos. Por isso, ela define democracia como "[...] o regime fundado na soberania popular e no respeito integral aos direitos humanos.” (BENEVIDES, 1996, p. 225). Essa compreensão é importante porque concebe a democracia dentro de um contexto político, social e de liberdade e justiça social. Além disso, a democracia depende de processos educativos. A autora entende a educação

[...] como a formação do ser humano para desenvolver suas potencialidades de conhecimento, de julgamento, de escolha para viver conscientemente em sociedade, o que inclui também a noção de que o processo educacional, em si, contribui tanto para conservar quanto para mudar valores, crenças, mentalidades, costumes e práticas. (BENEVIDES, 1996, p. 225).

De algum modo, essas reflexões aproximam-se das preocupações de John Dewey, quando postula que a democracia está articulada organicamente com a educação. Para Dewey (1979), a democracia implica não apenas o governo da maioria, mas a formação dos cidadãos para que pensem e participem na elaboração das políticas públicas e no julgamento dos resultados. A educação para a democracia ocorre, dentro desse horizonte, pela persuasão e pela liberdade individual, que não podem ser sacrificadas por qualquer ideologia. A formação do cidadão democrático envolve, segundo Benevides (1996), a tríade já formulada na Revolução Francesa: direitos civis, direitos sociais e solidariedade planetária, ou seja, os valores democráticos estão estritamente vinculados aos republicanos e dizem respeito ao "[...] reconhecimento da igualdade, o respeito aos direitos humanos e a vontade da maioria, legitimamente formada"(BENEVIDES, 1996, p. 228) e, igualmente, englobam:

a) a virtude do amor à igualdade, de que falava Montesquieu, e o consequente repúdio a qualquer forma de privilégio; b) o respeito integral aos direitos humanos, cuja essência consiste na vocação de todos - independentemente de diferenças de raça e etnia, sexo, instrução, credo religioso, julgamento moral, opção política ou posição social - a viver com dignidade, o que traz implícito o valor da solidariedade; c) o acatamento da vontade da maioria, legitimamente formada, porém com constante respeito pelos direitos das minorias, o que pressupõe a aceitação da diversidade e a prática da tolerância. (BENEVIDES, 1996, p. 231). 
No campo da educação, tanto no sentido lato quanto no âmbito escolar, a democracia vem ganhando espaços significativos, desde a fundamentação conceitual, a incorporação em políticas educacionais, até a construção de experiências democráticas de gestão. O problema é que nem sempre há clareza do que é democracia e de quais são suas implicações enquanto procedimento político (forma de gestar o poder), sendo formulada no âmbito das várias tradições intelectuais, de modo particular, da tradição pragmatista, especialmente de Dewey (1979), que a entende como valor universal e constitutiva de modos de vida. O autor defende a tese de que a democracia não é um dado natural, mas é resultante de processos educativos. A esse respeito, afirma: "Uma vez que a sociedade democrática repudia o princípio da autoridade externa, deve dar-lhe como substitutos a aceitação e o interesse voluntários, e unicamente a educação pode criá-los.” (DEWEY, 1979, p. 93). A democracia implica, dentro desse horizonte de compreensão, um processo educativo. Por meio dela, formam-se sujeitos críticos, éticos, participativos e responsáveis. A crítica que Dewey faz ao princípio da autoridade externa se justifica porque diferentes tradições buscaram amparo em autoridades externas, tanto religiosas quanto políticas, econômicas ou militares e, em nome delas, exerceram o poder. A democracia exige a superação do poder emanado de qualquer "autoridade externa", porque ela traz como exigência o princípio de que os cidadãos assumem efetivamente a condição de sujeitos. $O$ interesse pela participação não nasce espontaneamente, mas deve ser construído pela educação, ou seja, por meio de uma formação democrática.

Dewey (1979, p. 93) argumenta em defesa de uma compreensão ampla de democracia quando diz que ela “[...] é mais que uma forma de governo; é, primacialmente, uma forma de vida associada, de experiência conjunta e mutuamente comunicada [...]" Essa compreensão vai muito além da democracia concebida como procedimento formal em vista da eleição de determinados representantes. Ao afirmar que ela é mais do que uma forma de organização política, ele reconhece que ela é também uma forma de governar, embora vá muito além. A vida associada e a experiência conjunta não são formadas por forças externas ou metafísicas, mas constituídas pela educação. Decorre dessa compreensão o desafio de uma educação republicana capaz de formar sujeitos ativos e participantes nas tomadas de decisões sobre as coisas públicas. Para além da dimensão política, fundamenta-se uma perspectiva ética que implica uma formação do indivíduo, mas visando à convivência com os demais.

As reflexões de Dewey (1979) apontam para a necessidade de um sujeito ativo, o qual, por sua vez, implica um sujeito pensante e ético. Para ele, a educação é vital, pois é condição para uma vida ativa na sociedade. O autor ainda levanta 
questões importantes para uma reflexão sobre a influência da educação na formação democrática, pois ela pode auxiliar tanto para o crescimento das pessoas e das coletividades quanto para o fracasso. Sua contribuição aponta para uma compreensão de que a democracia é mais do que uma forma de governo, ou seja, é uma forma de vida associada, construída com outros sujeitos que possuem experiências próprias. Daqui decorrem inúmeros desafios para a educação tanto no sentido amplo quanto para a escola, em particular.

\section{EDUCAÇÃO ESCOLAR E DEMOCRACIA}

No caso brasileiro, desde a Constituição de 1988 e, de modo mais acentuado, após a aprovação da LDB de 1996, as políticas educacionais reforçam dois grandes pilares: a formação para a democracia e a formação para a cidadania. Isso não é fruto do acaso, mas resultante de lutas e pressão de grupos e organizações sociais em prol de uma sociedade democrática, de modo particular desde o final dos anos 1970.

Hoje existem muitas críticas relativas ao fracasso das políticas sociais e educacionais. No entanto, é preciso interrogar, em primeiro lugar, quais os indicadores que efetivamente revelam que as políticas educacionais não estão trazendo resultados positivos em relação à democracia e à cidadania e, em segundo, que entraves bloqueiam os avanços democráticos na sociedade brasileira como um todo? Em relação a essa segunda questão, é fundamental contextualizar a formação social e histórica brasileira, os interesses patrimonialistas, o papel das políticas assistencialistas, bem como as compensatórias que mais contribuem para a manutenção da estrutura dominante do que para uma transformação qualitativa.

Ao analisar as experiências democráticas no Brasil, pesquisadores reconhecem que elas ainda são muito frágeis. Para Benevides (1996), vários elementos comprometem uma democracia ativa: experiências de governos ditatoriais, cultura política oligárquica e desrespeito aos direitos humanos, com destaque ao indivíduo produtor, distribuidor e consumidor de bens e serviços. Com a redemocratização do país, na década de 1980, ganha espaço a ideia de que o desenvolvimento não ocorre apenas no âmbito econômico, mas também no âmbito social e político. É nesse contexto que uma educação política democrática e cidadã ganha destaque:

Hoje podemos afirmar que a cidadania é uma ideia em expansão; no entanto, a ação política continua desvalorizada e o cidadão pode ser visto apenas como o contribuinte, o consumidor, o demandante de benefícios individuais ou corporativos. E se- 
quer o princípio constitucional de escola para todos consegue ser cumprido. (BENEVIDES, 1996, p. 224).

A educação para a tolerância e a liberdade precisa estar fortemente vinculada às noções de igualdade e solidariedade. A educação para a democracia tem um lócus privilegiado, que é a educação escolar. Para Benevides (1996, p. 234), a escola é “[...] a única instituição cuja função oficial e exclusiva é a educação." Nesse sentido, não se pode pensar em uma democracia sem uma educação democrática, e essa tarefa não é exclusiva de governos ou de partidos, mas da sociedade como um todo, e ela exige tempo e paciência.

O que foi possível observar nos debates durante a campanha presidencial e as campanhas para governadores, em 2014, foi um baixo nível de argumentação política, o que, por conseguinte, comprometeu a formação cidadã. Entende-se que os processos eleitorais no âmbito da democracia representativa são importantes, visto que são momentos decisivos de eleição de representantes para os postos executivos e legislativos. Boa parte da campanha de 2014 foi marcada por ataques pessoais e por argumentos de exclusão do outro ao invés de confrontos transparentes e qualificados de ideias, valores e projetos políticos, socioeducativos e econômicos. Uma avaliação geral desse processo, tanto no primeiro quanto no segundo turno, permite concluir que a democracia avançou pouco do ponto de vista educativo e da formação cidadã, com exceções, é claro. Durante a campanha, manifestaram-se muitas ideias e posturas autoritárias, xenófobas e excludentes. Isso significa que avançamos pouco na construção de uma democracia efetiva, especialmente quando se trata de relações interpessoais e da convivência em uma sociedade complexa e plural. A democracia continua sendo, em grande parte, um procedimento meramente formal. A democracia continua sendo, em grande parte, um procedimento meramente formal. Um grande desafio é qualificar a democracia representativa por meio da configuração de partidos com ideologias (ideias) e valores republicanos, que tenham representatividade social e primem pela participação. Finalmente, a necessidade de a imprensa contribuir efetivamente na discussão de ideias, projetos e propostas de modo aberto e transparente.

Partindo desses pressupostos mais gerais, é fundamental questionar sobre as possibilidades de uma educação para a democracia no âmbito da escola. No que a escola pode contribuir para a formação democrática? Como ela pode desenvolver, nos seus espaços formativos, experiências que permitam qualificar os sujeitos em relação à participação, à resolução de conflitos e à gestão do espaço público? Como existem muitas concepções de democracia, é fundamental que as instituições discutam e teorizem a respeito. Nessa direção, é importante fundamentar uma crítica à concepção 
de democracia hegemônica que, ao primar por regras e procedimentos meramente formais, esvaziou a dimensão política da participação. A contribuição dos clássicos na fundamentação do debate é fundamental, embora seja necessário ir além, visto que existem inúmeras realidades emergentes que os clássicos não trataram. Disso, surge a necessidade de ler e interpretar os clássicos de forma crítica e criativa. É essencial aprofundar as diferentes tradições, desde Platão e Aristóteles, passando por autores modernos e contemporâneos, e ver como a democracia foi pensada nos diferentes contextos e de distintos pontos de vista e perspectivas. Alguns focaram suas virtudes e outros seus limites. Em alguns casos, o enfoque recaiu sobre os procedimentos formais na perspectiva da democracia como forma de governo. A tradição deweyana destacou a democracia do ponto de vista educativo, ou seja, considera a formação democrática. É nesse contexto que a escola ganha maior significação, pois ela se constitui num espaço de formação democrática tanto em relação à formulação dos pressupostos quanto na efetivação de experiências participativas.

O esforço para pensar a educação escolar na perspectiva da formação de sujeitos pensantes e criativos não é tarefa simples. Nesse sentido, é necessária uma preparação qualificada de professores para que possam conduzir os processos democráticos tanto em suas formulações conceituais quanto na realização de experiências práticas. Por vezes, há uma confusão relativa à democracia, especialmente em relação à condução pedagógica. Essa confusão, decorrente de uma concepção basista de democracia, entende que todos têm o mesmo poder. A democracia assegura esse princípio, mas é preciso atentar para o fato de que existem pessoas que precedem às novas gerações e que, pelo menos do ponto de vista teórico, já construíram experiências distintas. A educação democrática deve produzir um duplo movimento: criar condições para as aprendizagens dos que precedem as novas gerações e, ao mesmo tempo, criar condições para que as novas gerações façam suas experiências próprias. Esse processo exige uma pedagogia qualificada, bem como de pedagogos capacitados, caso contrário, crescem os riscos de ações e procedimentos autoritários. Os riscos de uma educação para a democracia são inerentes à própria democracia e os sujeitos envolvidos precisam estar sistematicamente vigilantes. Até que ponto a formação dos profissionais da educação está suprindo uma educação democrática no contexto das sociedades complexas? Até que ponto a escola possibilita a realização de experiências participativas e democráticas?

A escola enquanto instituição educativa permanece sendo fundamental na sociedade atual e é desafiada a contribuir efetivamente na formação integral dos alunos, perpassada por uma compreensão de educação crítica e emancipadora. Para 
tanto, é importante superar concepções de educação que priorizam apenas conteúdos e resultados quantitativos, os quais, muitas vezes, são usados para ranquear instituições. Além disso, a democracia é muito mais do que o direito de votar. É um exercício diário de formação e de prática que tem de ocorrer em todos os espaços, tanto na família quanto na escola, no trabalho e nos demais espaços públicos. É dentro dessa compreensão que Dewey (1979, p. 93) fala de democracia como modos de viver, conforme enunciado anteriormente, ou seja, como "[...] vida associada e de experiência conjunta." Uma gestão democrática desestabiliza posições e faz as pessoas saírem das zonas de conforto e comodismo. A democracia traz como exigência a convivência frente a diferentes posicionamentos que, por sua vez, geram conflitos. Os diferentes posicionamentos têm de ser confrontados e o diálogo coloca-se, nesse contexto, como possibilidade. As questões formuladas com profundidade e pertinência por Freire (1981), especialmente na pedagogia do oprimido, reforçam o compromisso de uma educação democrática.

A escola é desafiada a educar para a democracia e também a construir experiências democráticas envolvendo a comunidade escolar, não apenas nas situações críticas e de crises, mas em todos os momentos. Para Dewey (1979, p. 21), a escola é um ambiente especial de educação democrática.

\begin{abstract}
A primeira função do órgão social que denominamos escola é proporcionar um ambiente simplificado. Selecionando os aspectos mais fundamentais, e que sejam capazes de despertar relações da parte dos jovens, estabelece a escola, em seguida, uma progressão, utilizando-se dos elementos adquiridos em primeiro lugar como meio de conduzi-los ao sentido e compreensão real das coisas mais complexas.
\end{abstract}

Essas preocupações relativas à escola desafiam gestores e professores. Nessa direção, pode-se pensar com Paro (2007, p. 20), quando trata da educação para a democracia "[...] como função da escola pública." Para além das preocupações em desenvolver conteúdos próprios de cada disciplina, os professores são cidadãos e participam de inúmeros espaços sociais e políticos. Essas experiências são fundamentais para o aprofundamento, nos espaços escolares, de uma educação para a democracia, não de forma fragmentada ou incluída em alguma disciplina, mas transversalizando todo o conteúdo e toda a vivência da escola. Não há como pensar em qualidade da educação se essas questões não forem teorizadas e também vivenciadas.

Todos os estudantes e educadores precisam ser educados para a democracia, a qual, por sua vez, exige análises sobre as causas das desigualdades sociais e econômicas existentes na sociedade. Essas desigualdades, que são estruturais, criam obs- 
táculos à democracia, mas não podem impedir uma democratização do poder. Muito se discursa sobre a escola democrática, no entanto, persistem alguns desafios profundos e de difícil solução, embora não impossíveis de serem enfrentados. Muitas experiências são frustradas em consequência das estruturas burocráticas e dos comodismos que bloqueiam avanços críticos e inovadores. A democracia implica a socialização e o confronto de diferentes pontos de vista. Nesse sentido, ela é profundamente exigente. É muito mais fácil se apoiar em determinações externas ou nas complexas estruturas burocráticas para justificar determinados comportamentos. Sem uma predisposição do coletivo em participar de todas as instâncias e espaços de discussão e formulação de políticas no âmbito da escola, não há como falar em democracia de fato.

\section{CONSIDERAÇÕES FINAIS}

No decorrer das argumentações fundamentadas, fica evidente que o conceito de democracia não é consensual. Um primeiro esforço, nesse sentido, é de analisar com profundidade as diferentes tradições que foram se constituindo historicamente. Quando se fala que existem autores clássicos que trataram do tema em diferentes períodos e contextos, é porque eles ainda se constituem em referência. Nesse sentido, é fundamental um duplo movimento: o estudo desses autores e um posicionamento crítico que permita relativizar determinadas posições assumidas em razão de circunstâncias. Em cada contexto existem questões emergentes que precisam ser explicitadas, e são essas questões que interrogam a tradição.

No decorrer do presente artigo, colocam-se em evidência, mesmo com seus limites, a necessidade e os desafios para se pensar a democracia enquanto constitutiva de sujeitos capacitados para viverem socialmente. Decorre dessa compreensão que ela não é um dado exterior aos sujeitos, mas tem de ser constituída e formadora de modos de vida, portanto, de práticas pessoais e sociais. As contribuições de várias experiências desenvolvidas em países que compõem a obra organizada por Santos (2009), por exemplo, permitem pensar que a educação para a democracia ocorre em inúmeros espaços, para além da escola, embora a escola continue sendo um espaço privilegiado. As experiências democráticas construídas por movimentos e organizações sociais, nas lutas por direitos humanos, conforme discute Benevides (1996), em escolas, como destaca a pesquisa de Paro (2007), ou nas discussões de Dewey (1979), ressaltam que o tema precisa ser pesquisado, discutido e problematizado permanentemente. $\mathrm{O}$ conceito de democracia precisa ganhar densidade com discussões teórico-práticas, somente assim poderá ganhar vitalidade e contribuir nas discussões sobre educação 
para a democracia em contextos de sociedades complexas, nas quais a diversidade se faz intensamente presente.

Em contextos em que os interesses individuais tendem a se sobrepor às experiências sociais, a democracia precisa ganhar cada vez mais centralidade. A convivência social coloca-se como um desafio e depende, em grande parte, da capacidade de pensar a diversidade que precisa ser potencializada em vista do crescimento coletivo e não ser instrumentalizada para a exclusão de grupos, classes, organizações, gêneros, etc.

Os limites da democracia, apontados por diferentes tradições e sistematizados por Cunningham (2009), não podem ser desprezados. Eles vêm sendo formulados desde a antiguidade grega. No entanto, a democracia é uma possibilidade efetiva de enfrentamento e solução de problemas e conflitos. A educação tanto nos espaços informais ou formais quanto nos espaços escolares é desafiada a contribuir para a formação democrática. Evidentemente, isso implica mudanças profundas nas formas de trabalhar os conteúdos, nas discussões políticas e nas relações de poder. Isso tudo deve impactar a formação das crianças, jovens e adultos, ou seja, a superação do individualismo, da competição e das distintas formas de exclusão.

Mesmo com todos os problemas e contradições que lhe são inerentes, a escola merece um destaque especial. Com todas as críticas que vem sofrendo, muitas delas justificáveis, ela continua sendo um dos poucos espaços institucionais existentes na sociedade atual com potencialidade para aprofundar, tanto na teoria quanto na prática, experiências democráticas. A democracia torna-se efetiva quando a escola e outras organizações sociais contribuírem para formar sujeitos ativos, pensantes e participativos. Para que isso ocorra, não basta qualificar a democracia formal, embora ela seja importante. O desafio é avançar na consolidação de uma democracia de alta intensidade, para a qual a formação e a participação de sujeitos críticos são imprescindíveis. Além disso, é fundamental a participação dos distintos sujeitos envolvidos nas discussões e na tomada de decisões, que qualifiquem a cidadania e apontem para alternativas de sustentabilidade social, econômica e ambiental.

\section{REFERÊNCIAS}

ARISTÓTELES. A política. Tradução Mário da Gama Kury. 3. ed. Brasília: EdUnB, 1997.

BENEVIDES, M. V. Educação para a democracia. Lua Nova, São Paulo, n. 38, p. 223-237, 1996. 
CUNNINGHAM, F. Teorias da democracia: uma introdução crítica. Porto Alegre: Artmed, 2009.

DEWEY, J. Democracia e Educação: introdução à filosofia da educação. 4. ed. São Paulo: Nacional, 1979.

FREIRE, P. Pedagogia do Oprimido. 9. ed. Rio de Janeiro: Paz e Terra, 1981.

MACPHERSON, C. B. A democracia liberal: origens e evolução. Rio de Janeiro: Zahar, 1978.

NUSSBAUM, M. Sin fines de lucro: por qué la democracia necessita de las humanidades. Buenos Aires: Katz Editores, 2010.

PARO, V. H. Gestão escolar, democracia e qualidade do ensino. São Paulo: Ática, 2007.

PLATÃO. La República. Madrid: Edimat Libros, 2000.

SANTOS, B. S. (Org.). Democratizar a democracia: caminhos da democracia participativa. Rio de Janeiro: Civilização Brasileira, 2009.

SANTOS, B. S.; AVRITZER, L. Introdução: para ampliar o cânone democrático. In: SANTOS, Boaventura de Sousa (Org.). Democratizar a democracia: caminhos da democracia participativa. Rio de Janeiro: Civilização Brasileira, 2009.

TECQUEVILlE, A. A democracia na América: sentimentos e opiniões. São Paulo: Martins Fontes, 1977.

Endereço para correspondência: Rua Barão de Rio Branco, n. 375, Centro, 9260000, Casca, RS, Brasil; telmomarcon@gmail.com 